\title{
Antibacterial Efficacy of Metallic Nanoparticles using Plant Biomass
}

\author{
Syed Md Humayun Akhter and Faiz Mohammad* \\ Department of Applied Chemistry, Aligarh Muslim University, India
}

Submission: April 25, 2018; Published: May 25, 2018

*Corresponding author: Faiz Mohammad, Department of Applied Chemistry, Faculty of Engineering and Technology, Aligarh Muslim University, ALIGARH-202002, India, Tel: +91-9412623533; Email: faizmohammad54@rediffmail.com

Abstract

The emergence of nanotechnology in recent years has made a revolutionary impact in every aspect of the science, engineering and technology. Green synthesis of the metal nanoparticles using plant biomass is an emerging area of the research worldwide. These nanoparticles were investigated for their antibacterial efficacy and found to be the potential candidates to treat the resistant superbugs. Reviewed literature reveals that particle size plays an important role in the lysis of the bacterial cell wall. In the present review, we have focussed on the synthesis of metallic nanoparticles by using green route and evaluation of the antibacterial efficacy against various pathogenic bacterial strains

Keywords: Green synthesis; Metal Nanoparticles; Antibacterial efficacy

Abbreviations: SPR: Surface Plasmon Resonance; SERS: Surface-Enhanced Raman Scattering

\section{Introduction}

Discoveries in the past have shown that the physical and chemical properties of materials change significantly once the size of the materials is reduced to nanoscale in the range of 1 to $100 \mathrm{~nm}$ [1]. The development of nanotechnology has revolutionized the every aspect of the science, engineering and technology. In recent years, the multidimensional aspects of nanoparticles make them potential materials for applications in a wide variety of fields. The properties of nanoparticles are significantly different from their bulk counterparts. Nanoparticles show some unique properties such as Surface Plasmon Resonance (SPR), surface-enhanced Rayleigh scattering and Surface-Enhanced Raman Scattering (SERS) properties that make them the potential materials for optoelectronics, electronics, chemical sensing and biological applications [2]. Among the various materials, metallic nanoparticles have been used extensively by researchers worldwide.

The preparation of nanoparticles is done either through a top-down or a bottom-up approach. Various physical and chemical methods have also been employed for the preparation of nanoparticles by size reduction of bulk material by the top-down approach. However, the main drawback of this process is the imperfection of the surface structure. Besides this, the high energy consumption requirement during the preparation for maintaining high temperature and pressure is another limitation to this process. The bottom-up approach commonly uses the wet chemical process for the preparation of nanoparticles. However, extensive use of toxic and hazardous chemicals is a matter of great concern on the environment and living cells $[3,4]$.

The green synthesis of metal nanoparticles is the novel, environmental friendly and a busy area of research in which the preparation of metal nanoparticles employs the use of bacteria, fungus and plants. Based on this approach, plant extract has been used for the preparation of the inorganic nanomaterials. Plant-mediated green synthesis of metal nanoparticles is a fast, economical and produces highly stable nanoparticles. It is one pot synthetic approach, eco-friendly and safe for human therapeutic use. In contrast to the traditional method of synthesis, plant-based protocols meets all the criteria for green synthesis $[3,4]$.

Plant mediated green synthesis of metal nanoparticles

Green synthesis of the metal nanoparticles using medicinal plant extracts is currently under great exploration. A good number of works have been carried out in this direction where extracts of different parts of the plant are used for the preparation of metal nanoparticles. Metals such as gold, silver, palladium, copper, zinc, platinum etc. has successfully been prepared using the plant extracts.

\section{Intracellular preparation of metal Nanoparticles using plant biomass}

Plant biomass was used for the bioaccumulation of metal nanoparticles. However, it requires tiresome and expensive 
steps to recover the nanoparticles. There is a very little work reported on the use of plant biomass for the intracellular synthesis of metal nanoparticles. Among various plants explored so far included Brassica juncea, Berkheya coddii etc. were used for hyper-accumulation of gold. Besides, Media sativa, Sesbania dromondii, Avena sativa, Triticum aestivum, Festuca rubra etc. have been exploited for preparing various metallic nanoparticles.

\section{Extracellular preparation of metal nanoparticles by plant biomass}

Generally plant biomass is the repository of many phytochemicals hence they are also being used for the extracellular preparation of metal nanoparticles. In intracellular preparation, recovery of the prepared nanoparticles is a tiresome work. In contrast to it, plant extract mediated green synthesis is an easy and eco-friendly method.

\section{Plant extracts mediated facile green synthesis of metal nanoparticles}

Recently, phyto constituents of plant extracts were employed for reducing the metal ions. These routes are more favourable and their potential applications in the commercial field are also widely perceived. Plants are the source of the broad spectrum of metabolites so a good number of works have been reported where extracts from different parts of plants such as leaves, roots, stems, bark, flowers etc. have been used for the preparation of metal nanoparticles. Among the various nanometals explored so far nanoparticles of silver and gold has been studied extensively because of their large positive electrochemical potential [5]. The studies on the preparation of other metal nanoparticles have also been reported. It has also been observed that shape of nanoparticles reported were almost spherical and highly reactive fcc structure which supports its application at commercial level.

\section{Antibacterial Activities of Metal Nanoparticles}

The morphological and physiological characteristics of the nanometals make them a potential candidate for antibacterial activities. Size of the nanoparticles plays an important role in influencing the antibacterial activity. The smaller the size, better is the antibacterial activity [6]. Further, we focused on the work done by the researchers worldwide using the plant extracts for preparing the metal nanoparticles and their potential antibacterial activity.

\section{Gold nanoparticles}

To date, large numbers of research groups have focussed their attention on the green synthesis of gold nanoparticles and their potential activity against the common pathogenic bacteria. Au nanoparticles are considered to be the potent candidate as antibacterial agents due to their nontoxicity, ease of detection and photo thermal activity [7-9]. In another experiment, Lima et al. [10] observed the antibacterial efficacy against Escherichia coli and Salmonella typhi. They reported that these nanoparticles were effective against $90-95 \%$ of the bacterial colonies. Tiwari et al. [11] reported that gold nanoparticles showed better antibacterial activity against Gram-negative bacteria as compared to the Gram-positive. $\mathrm{Au}$ nanoparticles as compared to other nanometals are independent of ROS mechanism making them an ideal material to be applied as antibacterial agents.

\section{Silver nanoparticles}

Among the various nanoparticles explored so far, silver nanoparticles have also gained much popularity for their application as antibacterial. Recent studies show that $\mathrm{Ag}$ nanoparticles can induce pit formation on the cell wall of bacteria leading to its fragmentation [12,13]. Mie et al. [14] investigated the antibacterial potential of Ag nanoparticles against eight microorganisms and reported that these nanoparticles work better against the Gram-negative bacteria. Sondhi \& Salopek [15] prepared $\mathrm{Ag}_{2} \mathrm{O}$ nanoparticles and studied their antibacterial efficacy against Escherichia coli. They proposed that these nanoparticles halted the cell cycle at G2/M phase leading to DNA damage. The cells undergo oxidative stress and apoptosis was induced. However, further research is required to synthesize nano-Ag compounds and composites with minimum toxicity and maximum antibacterial efficacy.

\section{Zinc Nanoparticles}

$\mathrm{ZnO}$ is compatible with human skin making it a suitable candidate for textile and surfaces that come in contact with human body. Li et al. [16] observed the antibacterial efficacy of the ZnO nanoparticles against Escherichia coli and Staphylococcus by coating it on a plastic film. Azam et al. [17] evaluated in a comparative studies on three metal oxide nanoparticles i.e. $\mathrm{ZnO}, \mathrm{CuO}$, and $\mathrm{Fe}_{2} \mathrm{O}_{3}$ and their antibacterial efficacies against Gram-positive and Gram-negative bacteria. They concluded that $\mathrm{ZnO}$ nanoparticles showed better bactericidal activity as compared to other metal oxides. Furthermore Xie et al. [18] synthesized the ZnO nanoparticles and tested its efficacy against Campylobacter jejuni. They proposed a tentative mechanism for the antibacterial activity of thus synthesized $\mathrm{ZnO}$ nanoparticles.

\section{Copper nanoparticles}

The antibacterial activity of copper nanoparticles has been reported by many researchers worldwide. Ruparelia et al. observed the antibacterial efficacy of copper nanoparticles against Escherichia coli, Bacillus subtili, Staphylococcus aureus etc. Furthermore, they reported copper nanoparticles have better antibacterial effect against Bacillus subtilis. Azam et al. [19] tested the copper nanoparticles against two Gram positive and Gram-negative bacteria and concluded that size of nanoparticles plays a very important role in antibacterial efficacy.

Besides those mentioned above, metal nanoparticles of alumina, iron, titanium dioxide etc. showing antibacterial activity have also been reported. 


\section{Conclusion}

Because of the multidrug-resistant in superbugs, the development of new antibacterial agents is the need of the hour. The metallic nanoparticles particularly gold and silver are the promising tool for this present alarming situation. Further research is required to know the exact mechanism of antibacterial action of metallic nanoparticles. The stability of plant mediated synthesis of metal nanoparticles is another key issue to address. Therefore, more studies are required which will catalyze the synthesis of stable metallic nanoparticles with long shelf life.

\section{Acknowledgement}

The one of the authors (SMHA) acknowledges the financial support from the University Grant Commission (New Delhi) in the form of Maulana Azad National Fellowship for Minority Students.

\section{References}

1. Shah MA, Ahmad $T$ (2010) Principles of Nanoscience and Nanotechnology. New Delhi, Narosa Publishing House.

2. Dauthal P, Mukhopadhyay M (2016) Noble metal nanoparticles: plant-mediated synthesis, mechanistic aspects of synthesis, and applications. Industrial \& Engineering Chemistry Research 55(36): 9557-9577.

3. Gangula A, Podila R, Karanam L, Janardhana C, Rao AM (2011) Catalytic reduction of 4-nitrophenol using biogenic gold and silver nanoparticles derived from Breynia rhamnoides. Langmuir 27(24): 15268-15274.

4. Devi TB, Ahmaruzzaman M, Begum S (2016) A rapid, facile and green synthesis of $\mathrm{Ag} @ \mathrm{AgCl}$ nanoparticles for the effective reduction of 2, 4-dinitrophenyl hydrazine. New J Chem 40(2): 1497-1506.

5. Akhtar SMH, Mohammed F, Ahmed S (2016) Plant mediated green synthesis of metal nanoparticles for applications in medicine. Journal of Nanotechnology in Diagnosis and Treatment 4: 15-24.

6. Dizaj SM, Lotfipour F, Barzegar-Jalali M, Zarrintan MH, Adibkia $\mathrm{K}$ (2014) Antimicrobial activity of the metals and metal oxide nanoparticles. Materials Science and Engineering: C 44: 278-284.

7. Jia L, Zhang Q Li Q Song H (2009) The biosynthesis of palladium nanoparticles by antioxidants in Gardenia

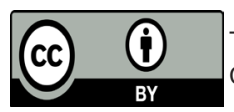

This work is licensed under Creative

Commons Attribution 4.0 License jasminoides Ellis: long lifetime nanocatalysts for $p$-nitrotoluene hydrogenation. Nanotechnology 20(38): 385601.

8. Lakshmipathy R, Reddy BP, Sarada NC, Chidambaram K, Pasha SK (2015) Watermelon rind-mediated green synthesis of noble palladium nanoparticles: catalytic application. Applied Nanoscience 5(2): 223228.

9. Yang X, Li Q Wang H, Huang J, Lin L, et al. (2010) Green synthesis of palladium nanoparticles using broth of Cinnamomum camphora leaf. Journal of Nanoparticle Research 12(5): 1589-1598.

10. Lima E, Guerra R, Lara V, Guzmán A (2013) Gold nanoparticles as efficient antimicrobial agents for Escherichia coli and Salmonella typhi. Chem Cent J 7(1): 11.

11. Tiwari PM, Vig K, Dennis VA, Singh SR (2011) Functionalized gold nano particles and their biomedical applications. Nano materials 1(1): 3163.

12. Yun H, Kim JD, Choi HC, Lee CW (2013) Antibacterial activity of CNT-Ag and GO-Ag nanocomposites against Gram-negative and Gram-positive bacteria. Bulletin of the Korean Chemical Society 34(11): 3261-3264.

13. Xiong Y, Adhikari CR, Kawakita H, Ohto K, Inoue K, et al. (2009) Selective recovery of precious metals by persimmon waste chemically modified with dimethylamine. Bioresour Technolo 100(18): 4083-4089.

14. Mie R, Samsudin MW, Din LB, Ahmad A, Ibrahim N, et al. (2014) Synthesis of silver nanoparticles with antibacterial activity using the lichen Parmotrema praesorediosum. Int J Nanomedicine 9: 121-127.

15. Sondi I, Salopek-Sondi B (2004) Silver nanoparticles as antimicrobial agent: a case study on E. coli as a model for Gram-negative bacteria. J Colloid Interface Sci 275(1): 177-182.

16. Li XH, Li WL, Xing YG, Jiang YH, Ding YL, et al. (2011) Effects of nanoZnO power-coated PVC film on the physiological properties and microbiological changes of fresh-cut "fuji" apple. Advanced Materials Research 152: 450-453.

17. Azam A, Ahmed AS, Oves M, Khan MS, Habib SS, et al. (2012) Antimicrobial activity of metal oxide nanoparticles against Grampositive and Gram-negative bacteria: a comparative study. Int J Nanomedicine 7: 6003-6009.

18. Xie Y, He Y, Irwin PL, Jin T, Shi X (2011) Antibacterial activity and mechanism of action of zinc oxide nanoparticles against Campylobacter jejuni. Appl Environ Microbiol 77(7): 2325-2331.

19. Azam A, Ahmed AS, Oves M, Khan MS, Memic A (2012) Size-dependent antimicrobial properties of $\mathrm{CuO}$ nanoparticles against Gram-positive and-negative bacterial strains. Int J Nanomedicine 7: 3527-3535.

\section{Your next submission with Juniper Publishers will reach you the below assets}

- Quality Editorial service

- Swift Peer Review

- Reprints availability

- E-prints Service

- Manuscript Podcast for convenient understanding

- Global attainment for your research

- Manuscript accessibility in different formats

( Pdf, E-pub, Full Text, Audio)

- Unceasing customer service

Track the below URL for one-step submission https://juniperpublishers.com/online-submission.php 